\title{
DISCUSSION
}

\section{An advanced experimental set-up for studying a monodirectional grout injection process}

\author{
J.-C. DUPLA, J. CANOU and D. GOUVENOT (2004) Ground Improvement, 8, \\ No. 3, 91-99
}

\section{A. Greenwood, Associate of Geotechnical Consulting Group, formerly Director of Cementation Piling and Foundations Ltd}

I applaud the authors for highlighting the process of hindered flow of particulate grouts at void constrictions in soils at the margins of injectability. This results in filtration, not just at the contact surface but deeper in the soil mass, and ultimately limits grout penetration.

Their experimental technique and presentation of data are excellent. There are, however, some apparently anomalous features of the data presented that merit further commentary.

First, the grout is said to have a c/e ratio of 0.4 and a density of $1 \cdot 19$. This would imply a specific gravity for the cement of $2 \cdot 27$, which is low for an ordinary Portland cement. Usually they have a specific gravity of 3.12.

Next, the test specimen had a volume of 51 and a dry density of $1.65 \mathrm{Mg} / \mathrm{m}^{3}$. After injection the weight of the setup had increased by $500 \mathrm{~g}$ when the sample was full of grout (Fig. 12). The increase is presumably attributable to the difference in weight of the cement and the water it has displaced in the pore spaces. For a grout with an initial c/e ratio of 0.4 this weight increase could be accounted for by the injection of 1.491 or 1.641 of grout depending on which specific gravity of cement applies. From this it can be derived that the porosity of the sample was between 0.3 and $0 \cdot 33$, depending on which value of the specific gravity of the cement is adopted. The lower value of specific gravity leads to the higher porosity, which, I believe, is most likely to be consistent with the uniform washed sands used in the experiment. This tends to confirm the low specific gravity of the cement.

From Fig. 7 it can be seen that $1000 \mathrm{~cm}^{3}$ of water was injected at a rate of $2.5 \mathrm{~cm}^{3} / \mathrm{s}$. This represents the pore volume in the 51 test sample, that is, representing a porosity of $0 \cdot 2$, which is not only very low for a uniform washed sand, but also at odds with the figures calculated above.

If, however, Figs 7 and 12 are mutually consistent, then the explanation for the apparent excess of cement in $1000 \mathrm{~cm}^{3}$ pore space must be the concentration of the grout mix in the pores due to filtration and simultaneous expulsion of water of equal volume. In that case the $500 \mathrm{~g}$ increase in weight represents a concentration of grout in the pores to a c/e ratio of 0.96 to 1.47 (according to the specific gravity of the cement) from the original 0.4. I would expect the unconfined crushing strength (UCS) of such cylindrical samples at 28 days to be about 6-16 MPa respectively, and about $1 \mathrm{MPa}$ for a c/e of $0 \cdot 4$.

Figures 15 and 16 show UCS values between $2 \cdot 1$ and 3.1 $\mathrm{MPa}$, so some concentration has certainly occurred, but not to the extent suggested in the previous paragraph. These strength correlations are unlikely to be precise, however, even with high-quality experimentation.

What the paper does illustrate clearly is the sensitivity of borderline soil gradings to filtration. The artificial washed and uniform soils chosen for clarity of laboratory experiment are far from real soils, which almost invariably contain a 'tail' of fines, the importance of which, in this context, is masked and minimised by the standard method of plotting grading curves. It is the finer element that generally has a disproportionately large influence on soil behaviour.

The empirical relations for groutability by permeation with particulate grouts are confirmed: the coarsest particles in the grout must be at least 10 times smaller than the finest particles in the soil to be grouted: or the $95 \%$ size of the grout particles must be smaller than the $5 \%$ size of the soil by a factor of 25. In effect, sands cannot be uniformly permeated by grouts containing ordinary Portland cement with particles up to $30-40 \mu \mathrm{m}$ in size.

\section{Authors' reply}

First of all, the authors would like to thank the discusser, Dr Greenwood, for his compliments concerning our experimental set-up and test results, and his interesting contribution to our work.

As far as the discusser's first comment is concerned, the authors agree that a density of 1.19 for the grout appears relatively low for this specific test, yielding a low specific gravity of the cement $(2 \cdot 27)$, and it might be slightly underestimated. After verification, it appears that grout density for other tests was, on an average, around 1.22, yielding a specific gravity value of 2.71 for the cement, which is more reasonable. Moreover, it should be noted that the cement we use is a CLK CEM III/C, with lower specific gravity (around $2 \cdot 8$ to $2 \cdot 9)$ than ordinary Portland cements, characterised by a specific gravity of $3 \cdot 13$, as indicated by the discusser.

As far as the discusser's comment concerning the injection of $1000 \mathrm{~cm}^{3}$ at a rate of $2.5 \mathrm{~cm}^{3} / \mathrm{s}$ is concerned, there is, in fact, a mistake in the text of the paper, in the first and fourth paragraphs, on page 95 . One should read $5 \mathrm{~cm}^{3} / \mathrm{s}$ for the flow rate instead of $2.5 \mathrm{~cm}^{3} / \mathrm{s}$, corresponding to the injection of about $2000 \mathrm{~cm}^{3}$ in $400 \mathrm{~s}$. This may be easily checked on Fig. 10 (saturation phase), showing that, for $t_{\mathrm{n}}=1$, corre- 
sponding to initial filling up of the column, a volume of water of about $2000 \mathrm{~cm}^{3}$ (exact value of $2090 \mathrm{~cm}^{3}$ read in data file) has been injected into the sand column.

As far as the following comment concerning the unconfined compressive strength (UCS) of grouted sand is concerned, owing to the indications given in the previous paragraph, it appears that the concentration of the grout within the porous space is in fact about 0.60 , instead of 0.96 as indicated by the discusser. It is therefore normal to find compressive strength values of about $2-3 \mathrm{MPa}$, lower than the typical values of 6-16 MPa as indicated by the discusser.

We agree with the discusser's subsequent comment relative to the predominant influence of fine particle fraction within the sand on filtration and injectability properties of the grout. Other specific tests, not presented in the paper, carried out by the authors on clean sands containing small fractions of fine particles have shown the significant influence of fines content on groutability.

Finally, we agree with the discusser's last comment concerning empirical criteria generally used for evaluating permeation groutability. However, it should be noted that, for a given sand corresponding to a given grain size distribution curve, these criteria do not take into account the influence of density index or relative density (characterising a dense, medium or loose arrangement), which indeed has a significant influence on groutability. 